\title{
Spectral analysis of overlapped absorption bands of binary mixtures - an application on combination of pseudoephedrine sulphate and loratadine mixture
}

Hayam M. Lotfy ${ }^{1}$, Sara El-Hanboushy ${ }^{1 *}$, Yasmin M. Fayez ${ }^{2}$ and Mohamed Abdelkawy ${ }^{1}$

\begin{abstract}
Background: Simple, specific, accurate, and precise spectrophotometric methods are progressed and validated for concurrent analysis of pseudoephedrine sulphate (PSE) and loratadine (LOR) in their combined dosage form depending on spectral analysis procedures. In this binary mixture, pseudoephedrine (PSE) could be determined by using its resolved spectrum of zero-order absorption at $256.8 \mathrm{~nm}$ after subtraction of the spectrum of $L O R$, and also it could be determined in existence of the spectrum of LOR by different methods including absorption correction method (AC) at $256.8 \mathrm{~nm}$ and $280 \mathrm{~nm}$, dual wavelength method (DW) at 254 $\mathrm{nm}$ and $273 \mathrm{~nm}$, induced dual-wavelength method (IDW) at $230 \mathrm{~nm}$ and $263 \mathrm{~nm}$, and ratio difference method $(\mathrm{RD})$ at $256.8 \mathrm{~nm}$ and $270 \mathrm{~nm}$. Loratadine (LOR) in the binary mixture could be determined either by direct analysis at $280 \mathrm{~nm}$ without any contribution from the spectrum of PSE or through its recovered spectrum of zero-order absorption via constant multiplication method (CM) using plateau region $(277-326 \mathrm{~nm})$. Also, concurrent determination for PSE and LOR in their overlapped binary mixture could be achieved by applying induced amplitude modulation (IAM) method.

Results: Specificity of the proposed spectrophotometric methods was examined by the analysis of prepared mixtures in laboratory and was applied successfully for pharmaceutical dosage form analysis which has the cited drugs without additive contribution. The proposed spectrophotometric methods were also validated as per the guidelines of $\mathrm{ICH}$. Statistical comparison was performed between the obtained results with those from the official methods of the cited drugs, using one-way ANOVA, $F$ test, and Student's $t$ test, and the results exhibit insignificant difference concerning precision and accuracy.
\end{abstract}

Conclusions: The previously proposed spectrophotometric methods could be easily used accurately and precisely for simultaneous determination of the studied binary mixture with simple manipulation procedures.

Keywords: Absorbance correction, Constant multiplication, Dual-wavelength, Induced amplitude modulation method, Induced dual-wavelength, Loratadine, Pseudoephedrine sulphate, Ratio difference

\footnotetext{
* Correspondence: sara.rasheed@fue.edu.eg

${ }^{1}$ Pharmaceutical Chemistry Department, Faculty of Pharmaceutical Sciences and Pharmaceutical Industries, Future University in Egypt, End of 90th St., 5th Settlement, New Cairo, Cairo 11835, Egypt

Full list of author information is available at the end of the article
} 


\section{Background}

Combinations of pseudoephedrine sulphate (PSE) with loratadine (LOR) are frequently prescribed to treat cold and relieve symptoms of allergic rhinitis due to seasonal changes [1].

Pseudoephedrine (PSE) [(S, S) methylamino-1-phenylpropan-1-ol] as in Fig. 1a acts as a sympathomimetic agent so it could be used as a decongestant drug [1]. Various spectrophotometric methods were established for the determination of pseudoephedrine [2-4]. Several chromatographic methods were applied for the determination of PSE containing HPLC [5-10], HPTLC [11-13], GC [14, 15], and CE [16, 17], and also, many electrochemical methods were reported [18-20].

Antihistamines are used to treat allergic reactions. One of their major side effects is the sedating effect which makes restriction for their use and so second-generation antihistamines commonly prescribed now. Loratadine (LOR) [ethyl 4-(8-chloro-5, 6 -dihydro-11H-benzo 5, 6 cyclohepta [1,2] pyridin-11-ylidene)-1-piperidinecarboxylate] as in Fig. 1b is a non-sedating, long-acting secondgeneration $\mathrm{H}_{1}$ receptor blocker. It is used for treatment of allergy cases including urticaria and rhinitis [1].

Various methods were established for analysis of LOR and its metabolite (desloratadine) in pharmaceutical formulations and in plasma of human containing spectrophotometric methods [2, 21, 22] and chromatographic methods including HPLC [6, 9, 23-25], HPTLC [12, 13, 26], and GC $[27,28]$. In addition, several electrochemical and polarographic methods were reported [29-32].

The survey of the literature shows different analytical methods for concurrent analysis of both PSE and LOR. Various chromatographic methods were established for the determination of the two analytes [33-35]. Other methods contain multi-wavelength spectroscopy [35], chemometric treatment of spectrophotometric data [36], first derivative spectroscopy [33].

The aim of this work is to create simple spectrophotometric methods which were able to resolve the spectral overlapping of PSE and LOR. The proposed spectrophotometric methods could be easily used accurately and precisely for simultaneous determination of the studied binary mixture with simple manipulation procedures. The proposed methods could be used in the analysis of their market formula named Clarinase ${ }^{\circ}$ tablet. A comparative study was made between the obtained results to check the efficiency of the proposed methods in the estimation of the cited drugs.

\section{Theoretical background}

Induced amplitude modulation method (IAM)

This method [37] is an extension for amplitude modulation method (AM) and advanced amplitude modulation (AMM) [37].

Ratio spectra of the mixture was obtained by dividing the mixture by the normalized spectrum of the extended drug as a divisor $\left(Y^{\prime}\right)$; this normalized spectrum is obtained by dividing the entire spectrum of $Y$ by its relative concentration to get a new spectrum which acts as the desired analyte's absorptivity $\left(a_{\mathrm{Y}}\right)$ against all the wavelengths which had been measured. This method can be clarified by using the following equations:

$$
\begin{aligned}
& \because\left[A_{1}\right] /\left[a_{Y}\right]=\left[a_{X} C_{X}\right] /\left[a_{Y}\right]+\left[C_{Y}\right] /\left[C_{Y}^{\prime}\right] \\
& \therefore P_{M i x}=a_{r} C_{X}+C_{Y}
\end{aligned}
$$

where $P_{\text {Mix }}$ is the recorded amplitude of $X$ and $Y$ mixture and $a_{\mathrm{r}}$ is the absorptivity ratio $\left\{\left[a_{X}\right] /\left[a_{Y}\right]\right\}$ which is obtained from the division of the normalized spectra of both pure component $X$ and $Y$, conjointly, while $C_{Y}$ is the amplitude which is recorded at the extended region which parallel to axis of wavelength<smiles>CCOC(=O)N1CCC(=C2c3ccc(Cl)cc3CCc3cccnc32)CC1</smiles>

a

b

Fig. 1 Structural formulae for a pseudoephedrine sulphate and $\mathbf{b}$ loratadine 
which could be modulated directly to the recorded concentration of $\mathrm{Y}$.

Contribution of $\mathrm{Y}$ is canceled by subtraction of $\left[\mathrm{C}_{Y}\right] /$ $\left[C_{Y}^{\prime}\right]$ to get $\left[a_{X} C_{X}\right] /\left[a_{Y}\right]$ followed by multiplication by spectrum $\left[a_{Y}\right] /\left[a_{X}\right]$ which is the ratio spectrum of the normalized spectra of $Y$ and $X$ :

$$
\begin{aligned}
& P_{(X)}=\left[a_{X} C_{X}\right] / a_{Y} *\left[a_{Y}\right] /\left[a_{X}\right] \\
& \therefore P_{(X)}=C_{X}
\end{aligned}
$$

The concentration of both $X$ and $Y$ could be modified to the actual concentration via substitution in regression equation which represent the amplitude of the ratio spectra of different concentrations of $X$ and $Y$, separately using normalized $Y$ as a divisor.

$$
C_{\text {Recorded }}=\text { slope } C_{\text {Actual }} \pm \text { intercept }
$$

The slope here is around unity, and the intercept is approximately equal zero. $C_{\text {Recorded }}$ is the amplitude which have been modulated correlative to the concentrations of $X$ or $Y$.

\section{Experimental}

\section{Devices and operating system}

The analysis was performed using a Shimadzu UV-1800 spectrophotometer attached to ACER computer. Quartz cells $(1.0 \mathrm{~cm})$ were used for recording the absorption spectra of both reference and test solutions at the range of $200-400 \mathrm{~nm}$.

\section{Materials}

\section{Authentic materials}

PSE and LOR were kindly given by Mina Pharm Company. The purity was detected as $99.56 \pm 0.42$ and $100.06 \pm 0.75$ for PSE and LOR, conjointly as stated in the official USP methods [38].

\section{Dosage form}

Clarinase $^{\circ}$ tablets were used with batch number 4JRPG24B02. Every tablet is claimed to have $120.0 \mathrm{mg}$ PSE and $5.0 \mathrm{mg}$ LOR, produced by Schering-Plough Company and obtained from the local market.

\section{Chemicals and solvents}

Hydrochloric acid was kindly supplied from El Nasr Chemicals \& Pharmaceutical Company, Cairo, Egypt, while distilled water was obtained using Ultra-Pure Water System "Aquatron" (Staffordshire, England) apparatus.

\section{Standard solutions}

\section{Standard stock solutions}

Preparation of stock solutions of PSE $(1500.0 \mu \mathrm{g} / \mathrm{mL})$ and LOR $(100.0 \mu \mathrm{g} / \mathrm{mL})$ was carried out by dissolving
$150.0 \mathrm{mg}$ and $10.0 \mathrm{mg}$ of PSE and LOR, conjointly in 0.1 $\mathrm{M} \mathrm{HCl}$ in100-mL volumetric flask; then, the volume was adjusted till the mark by using the same solvent and kept at the refrigerator.

\section{Procedure \\ Spectrophotometric scanning of PSE and LOR}

Solutions of PSE $(240.0 \mu \mathrm{g} / \mathrm{mL})$ and LOR $(10.0 \mu \mathrm{g} / \mathrm{mL})$ were prepared using their standard stock solutions $(1500.0 \mu \mathrm{g} / \mathrm{mL})$ for PSE and $(100 \mu \mathrm{g} / \mathrm{mL})$ for LOR and scanned in a wavelength region $200-400 \mathrm{~nm}$ against 0.1 $\mathrm{M} \mathrm{HCl}$ as blank; then, their spectra of zero-order absorption were obtained.

\section{Construction of calibration graphs}

Aliquots equivalent to $1800.0-12,000.0 \mu \mathrm{g}$ PSE and $50.0-300.0 \mu \mathrm{g}$ LOR had been transmitted from their stock solutions of PSE $(1500.0 \mu \mathrm{g} / \mathrm{mL})$ and LOR $(100.0 \mu \mathrm{g} / \mathrm{mL})$ to two separate sets of volumetric flasks $(10 \mathrm{~mL})$; then using $0.1 \mathrm{M} \mathrm{HCl}$, the volume was adjusted till the mark. Scanning of the spectra of absorption of previously performed standard solutions was conducted in the region from $200-400 \mathrm{~nm}$ and kept directly at the computer. The calibration graphs were done using the average of three experiments.

The calculation of the absorption factor was performed by taking the average ratio of absorbance at $256.8 \mathrm{~nm}$ and $280 \mathrm{~nm}\left(A_{256.8 \mathrm{~nm}} / A_{280 \mathrm{~nm}}\right)$ of different concentrations of LOR. In addition, the equality factor of LOR was calculated by taking the average ratio of absorbance at $230 \mathrm{~nm}$ and $263 \mathrm{~nm}\left(A_{230 \mathrm{~nm}} / A_{263 \mathrm{~nm}}\right)$ of different concentrations of LOR.

Calibration graphs of zero-order spectra based on absorbance for SS, DW, IDW, $\mathrm{D}^{\mathbf{0}}$, and CM Construction of calibration graphs of PSE was carried out by plotting the following: the absorbance at $256.8 \mathrm{~nm}$ for SS and the absorbance difference between $(254 \mathrm{~nm}, 273 \mathrm{~nm})$ for DW and $\left[A_{263 \mathrm{~nm}}-\right.$ (eq. factor) LOR $\left.A_{230 \mathrm{~nm}}\right]$ for IDW; then, all of the previously mentioned measures were performed against the correlative PSE concentrations while for direct measurement and CM method for LOR, construction of calibration graphs of LOR was based on plotting the absorbance at $280 \mathrm{~nm}$ and $250 \mathrm{~nm}$, conjointly against the correlative LOR concentrations; and then, equations of regression were accurately computed.

Calibration graphs based on amplitude of ratio spectra: for RD and IAM methods For RD method, previously stored spectra of zero-order absorption of PSE were divided by the spectrum of absorption of LOR $(30.0 \mu \mathrm{g} / \mathrm{mL})$; then, the difference between $256.8 \mathrm{~nm}$ and $270 \mathrm{~nm}$ was recorded. Construction of calibration graph was based on plotting the amplitude difference against 
the correlative PSE concentrations while for IAM method, previously stored spectra of zero-order absorption of LOR were divided by the spectrum of absorption of normalized LOR, and the constant value of each spectrum at wavelength region $(277-326 \mathrm{~nm})$ was recorded. Construction of calibration graph was based on plotting the constant value against correlative LOR concentrations then equations of regression were accurately computed. For IAM method, previously stored spectra of zero-order absorption of PSE were divided by the absorption spectrum of normalized PSE to get ratio spectrum and the constant value of each at wavelength region $(235-250 \mathrm{~nm})$ was recorded. Construction of calibration graph was based on plotting constant value against correlative PSE concentrations; then, equation of regression was accurately computed.

\section{Analysis of prepared mixtures in laboratory}

Aliquots were accurately transferred from stock solutions $(1500.0 \mu \mathrm{g} / \mathrm{mL})$ of PSE and $(100.0 \mu \mathrm{g} / \mathrm{mL})$ of LOR. Prepared mixtures in laboratory with various ratios of the mentioned drugs were prepared, and the volume was adjusted till the mark by $0.1 \mathrm{M} \mathrm{HCl}$. Scanning of spectra of previously prepared mixtures was carried out at wavelength region (200-400 nm) and kept at the computer.

\section{Manipulation of the spectra of zero-order absorption of the mixtures}

For determination of PSE Absorption correction method (AC): Using the spectra of zero-order absorption of every laboratory previously prepared mixtures, the absorbance was measured at $256.8 \mathrm{~nm}$ and $280 \mathrm{~nm}$, and by using the calculated LOR absorption factor, the concentration of PSE in each laboratory previously prepared mixture was obtained using relative equation of regression at $256.8 \mathrm{~nm}$. Dual wavelength method (DW): Using the spectrum of absorption of every laboratory previously prepared mixture, the absorbance was measured at $254 \mathrm{~nm}$ and $273 \mathrm{~nm}$. Difference in absorbance was calculated. PSE concentration in every laboratory previously prepared mixture was obtained using the relative equation of regression.

Induced Dual wavelength method (IDW): Using the spectrum of absorption of every laboratory previously prepared mixtures, the absorbance was measured at 263 $\mathrm{nm}$ and $230 \mathrm{~nm}$; then, difference using the equality factor of LOR was calculated $\left(A_{263 \mathrm{~nm}}-\text { (eq. factor }\right)_{\mathrm{LOR}}$ $\left.A_{230 \mathrm{~nm}}\right)$. PSE concentration in every laboratory previously prepared mixture was obtained using the relative equation of regression.

For determination of LOR Direct spectrophotometric determination: Using the spectrum of zero-order absorption of every laboratory previously prepared mixture, the absorbance was measured at $280 \mathrm{~nm}$. The concentration of LOR in each laboratory previously prepared mixture was obtained using the relative equation of regression.

\section{Manipulation of ratio spectra of laboratory previously prepared mixtures using LOR $(30.0 \mu \mathrm{g} / \mathrm{mL})$}

The scanned spectrum of zero-order absorption of every laboratory previously prepared mixture was divided by the spectrum of absorbance of LOR $(30.0 \mu \mathrm{g} / \mathrm{mL})$ to get ratio spectra.

Constant multiplication method paired with spectrum subtraction method (CM-SS) for PSE and LOR The constant of every ratio spectrum of mixture was measured in the wavelength region from $(277-326 \mathrm{~nm})$ of each ratio spectrum. The spectrum of zero-order absorption of LOR was obtained through multiplication of the value of constant by the spectrum of the divisor (LOR $30.0 \mu \mathrm{g} / \mathrm{mL}$ ). The resolved spectrum of zero-order absorption of PSE $\left(D^{0}\right)$ was obtained after spectrum subtraction of the attained LOR-D ${ }^{0}$ from the correlative laboratory previously prepared mixture $\mathrm{D}^{0}$. The concentration of PSE and LOR in each laboratory previously prepared mixture was obtained using relative equations of regression at $256.8 \mathrm{~nm}$ for PSE and $250 \mathrm{~nm}$ and $280 \mathrm{~nm}$ for LOR.

Ratio difference method for PSE (RD) Using the obtained ratio spectrum of each mixture, the amplitude difference between 256.8 and $270 \mathrm{~nm}$ was calculated. The concentration of PSE in every laboratory previously prepared mixture was attained using relative equation of regression.

\section{Manipulation of ratio spectra of previously prepared mixtures by using normalized spectra as a divisor}

Induced amplitude modulation method for PSE and LOR (IAM) The ratio spectrum was obtained by division of scanned spectrum of zero-order absorption of every laboratory previously prepared mixture over the spectrum of absorption of normalized LOR, then the constant for each mixture at wavelength region (277$326 \mathrm{~nm}$ ) was measured, and then subtraction of the value of constant of each mixture from its correlative ratio spectrum was conducted followed by multiplication by the recovery spectrum (computed by dividing normalized spectra of standard LOR by standard PSE) to get constant relative to PSE. The concentrations of PSE and LOR were accurately calculated from their relative equations of regression.

\section{Assessment of pharmaceutical dosage form}

Ten tablets of Clarinase ${ }^{\infty}$ were accurately weighed, the average was computed, and then, they were grinded to 
obtain fine powder. An accurate amount equal to one tablet (containing $1200 \mu \mathrm{g}$ of PSE and $50 \mu \mathrm{g}$ LOR) were accurately transmitted to $100-\mathrm{mL}$ beaker followed by the addition of $50-\mathrm{mL} 0.1 \mathrm{M} \mathrm{HCl}$; then, sonication of the solution was performed using ultrasonic bath for a period of 5 min. The solution was filtered using filter paper (Whatman No.10 filter paper with pore size $=11 \mu \mathrm{m}$ ) into $100-\mathrm{mL}$ volumetric flasks. Using $0.1 \mathrm{M} \mathrm{HCl}$, the volume was adjusted till the mark. Appropriate dilution was performed to get final concentration claimed to contain $240 \mu \mathrm{g} / \mathrm{mL}$ PSE and $10 \mu \mathrm{g} / \mathrm{mL}$ LOR. The proposed methods were applied for the analysis of the studied drugs through the procedures previously cited under analysis of prepared mixtures in laboratory for every method. Using relative equations of regression, PSE and LOR concentrations were calculated.

\section{Results and discussion}

The spectra of zero-order absorption of PSE and LOR in $0.1 \mathrm{M} \mathrm{HCl}$ show partial overlapping (Fig. 2). The aim of this work is to create simple, accurate, and sensitive methods for concurrent PSE and LOR determination either in their authentic form or their combined pharmaceutical formulation with acceptable precision, besides statistically comparing the proposed methods' ability for the determination the two cited drugs.

Experimentally, different types of solvents such as 0.1 $\mathrm{M} \mathrm{HCl}$ and methanol were tried; $0.1 \mathrm{M} \mathrm{HCl}$ was found to be the best solvent for extraction PSE and LOR from the pharmaceutical dosage form (Clarinase ${ }^{\circ}$ ) and was approved by reported methods $[33,35,39,40]$ without any interference from the excipient satisfactory results for the two drugs PSE and LOR regarding selectivity and precision.

By scanning spectra of the absorption of PSE (at higher concentration $\geq 180.0 \mu \mathrm{g} / \mathrm{mL}$ ) and $\mathrm{LOR} \geq 5.0 \mu \mathrm{g} / \mathrm{mL}$ in $0.1 \mathrm{M} \mathrm{HCl}$, PSE spectrum shows two maxima at $208.0 \mathrm{~nm}$ and $256.8 \mathrm{~nm}$, while LOR has two maxima at $250 \mathrm{~nm}$ and $280 \mathrm{~nm}$. Using these higher PSE and LOR concentrations allows the concurrent determination of both cited drugs without LOR enrichment, thus minimizing the error which may be occurred during calculation of claimed LOR. In the region of wavelength of 200-269 nm, severely overlay of spectral bands was observed while LOR spectrum is extended over PSE above this region allowing its direct determination at $280 \mathrm{~nm}$ (Fig. 2). For attaining best resolution and quantifying every drug without contribution from the other at wavelength region of 220-300 $\mathrm{nm}$, different spectrophotometric methods were applied, keeping in mind the mentioned linearity for the two cited drugs $(180.0-1200.0 \mu \mathrm{g} / \mathrm{mL}$ and $5.0-30.0 \mu \mathrm{g} / \mathrm{mL}$ for PSE and LOR, conjointly) and their ratio in the pharmaceutical dosage form (LOR: PSE, 1:24). Satisfactory results were achieved concerning their bulk powder, laboratory previously prepared mixtures pharmaceutical formulation without needing of initial separation.

\section{Manipulation of spectra of the zero-order absorption of the previously prepared mixtures For determination of $L O R$}

The spectra of zero-order absorption of each laboratory previously prepared mixture were directly

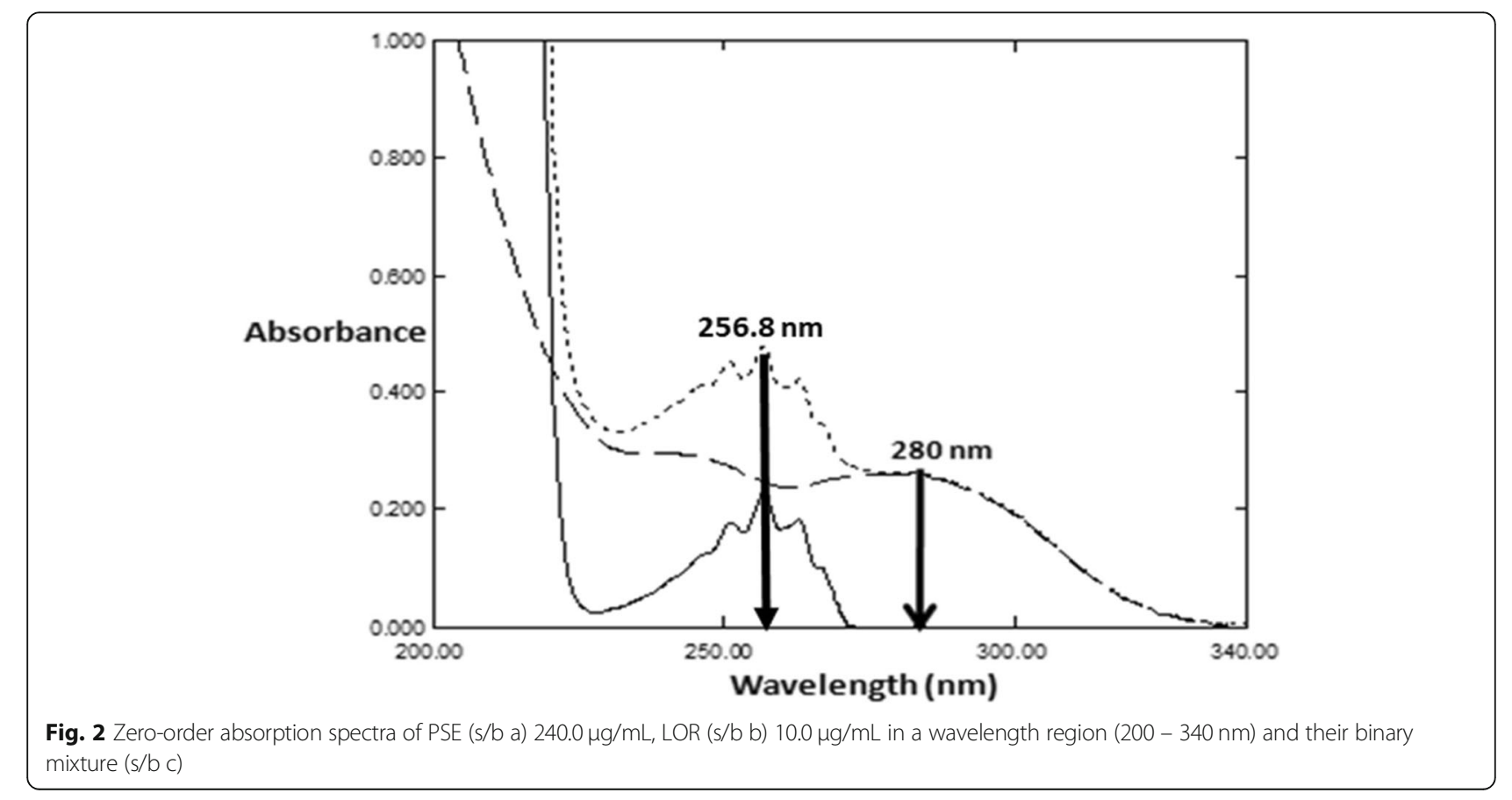


measured at $280 \mathrm{~nm}$ without any interference of PSE; then, the concentration of LOR in every mixture was determined through its relative regression equation at its maxima $280 \mathrm{~nm}$ as shown in Fig. 2.

A linear correlation was obtained between the values of the absorbance of LOR at its $\lambda_{\max } 280 \mathrm{~nm}$ and the corresponding concentrations $(5.0-30.0 \mu \mathrm{g} / \mathrm{mL})$, and then the regression equation was accurately computed as shown in Table 1.

\section{For determination of PSE}

Absorption correction method for PSE (AC) In this method $[41,42]$, resolution of the absorbance corresponding to PSE in the mixture could be calculated by using the absorption factor of LOR at 256.8 and $280 \mathrm{~nm}$. Recording the spectra of zero-order absorption of PSE and LOR in the range of wavelength 200-340 nm was performed, as shown in Fig. 2. It was found that the two spectra of PSE and LOR are strictly overlapped at $(200-275 \mathrm{~nm})$ where PSE has maxima $256.8 \mathrm{~nm}$ while LOR shows no interference at $280 \mathrm{~nm}$. The spectra of zero-order absorption of LOR standard stock solutions with various concentrations were recorded at the wavelength region of $200-400 \mathrm{~nm}$. The value of absorption factor was computed which is the ratio between the absorbance at $256.8 \mathrm{~nm}$ and $280 \mathrm{~nm}\left(A_{256.8 \mathrm{~nm}} / A_{280 \mathrm{~nm}}\right)$, and it was found to be 0.952 so the absorbance of PSE in the mixture at $256.8 \mathrm{~nm}$ could be calculated after multiplication of this factor by absorbance of mixture at $\left.280 \mathrm{~nm}\left(A_{256.8 \mathrm{~nm}} / A_{280 \mathrm{~nm}}\right) \times A_{280 \mathrm{~nm}}\right]$ as shown in Fig. 2. Quantitative estimation of PSE at $256.8 \mathrm{~nm}$ in their mixture (LOR + PSE) was carried out by subtracting LOR absorbance value at $256.8 \mathrm{~nm}$ from the mixture's recorded absorbance at $256.8 \mathrm{~nm}$, using the following equation:

$$
\begin{aligned}
& \text { Absorbance of PSE at } 256.8 \mathrm{~nm}=\mathrm{A}_{256.8 \mathrm{~nm}} \\
& (\mathrm{LOR}+\mathrm{PSE})-\left[\left(\mathrm{A}_{256.8 \mathrm{~nm}} / \mathrm{A}_{280 \mathrm{~nm}}\right) \times \mathrm{A}_{280 \mathrm{~nm}}\right. \\
& (\mathrm{LOR}+\mathrm{PSE})] . \text { Absorbance of PSE at } 256.8 \mathrm{~nm} \\
& =\mathrm{A}_{256.8 \mathrm{~nm}}(\mathrm{LOR}+\mathrm{PSE})-\left[(0.952) \times \mathrm{A}_{280 \mathrm{~nm}}(\mathrm{LOR}+\mathrm{PSE})\right]
\end{aligned}
$$

where $A_{256.8 \mathrm{~nm}}(\mathrm{LOR}+\mathrm{PSE})$ and $A_{280 \mathrm{~nm}}(\mathrm{LOR}+\mathrm{PSE})$ are the absorbance of the mixture at $256.8 \mathrm{~nm}$ and $280.0 \mathrm{~nm}$, and $A_{256.8 \mathrm{~nm}} / A_{280 \mathrm{~nm}}$ is the absorption factor.

The concentration of PSE in each mixture was calculated from its equation of regression which represents linear correlation between the absorbance values of PSE at its $\lambda_{\max } 256.8 \mathrm{~nm}$ against the relative concentrations $(180.0-1200.0 \mu \mathrm{g} / \mathrm{mL})$, and then, equation of regression was accurately computed as shown in Table 1. This method is restricted for binary mixture analysis in which the drug of interest is

\begin{tabular}{|c|c|c|c|c|c|c|c|c|}
\hline \multirow{2}{*}{$\begin{array}{l}\text { Drug name } \\
\text { methods }\end{array}$} & \multicolumn{5}{|l|}{ PSE } & \multicolumn{3}{|l|}{ LOR } \\
\hline & $\begin{array}{l}D^{0}(256.8 \\
n m)(S S)\end{array}$ & DW & IDW & $\mathrm{RD}$ & IAM & $\begin{array}{l}\mathrm{D}^{0}(280 \mathrm{~nm}) \\
\text { (Direct measurement or } \\
\mathrm{CM})\end{array}$ & $\begin{array}{l}\mathrm{D}^{0}(250 \mathrm{~nm}) \\
(\mathrm{CM})\end{array}$ & IAM \\
\hline $\begin{array}{l}\text { Range }^{a} \\
(\mu g / m L)\end{array}$ & $180.00-1200.00$ & & & & & $5.00-30.00$ & & \\
\hline \multicolumn{9}{|l|}{ Regressions parameters } \\
\hline Slope & 0.0009 & 0.0006 & 0.0006 & 0.0014 & 1.0010 & 0.0260 & 0.0278 & 0.9847 \\
\hline Intercept & 0.0028 & 0.0059 & 0.0184 & 0.01196 & 0.1560 & 0.0019 & 0.0031 & 0.0749 \\
\hline $\begin{array}{l}\text { Correlation coefficient }{ }^{\mathrm{b}} \\
(r)\end{array}$ & 0.9999 & 0.9999 & 0.9999 & 0.9999 & 1.0000 & 0.9999 & 0.9999 & 0.9999 \\
\hline Accuracy (mean $\pm S D$ ) & $99.59 \pm 0.86$ & $\begin{array}{l}98.51 \pm \\
0.42\end{array}$ & $\begin{array}{l}99.42 \pm \\
0.76\end{array}$ & $\begin{array}{l}99.28 \pm \\
0.83\end{array}$ & $\begin{array}{l}100.04 \pm \\
0.23\end{array}$ & $101.06 \pm 0.49$ & $\begin{array}{l}100.55 \pm \\
0.33\end{array}$ & $\begin{array}{l}100.88 \pm \\
0.27\end{array}$ \\
\hline \multicolumn{9}{|l|}{$\begin{array}{l}\text { Precision } \\
( \pm \% R S D)\end{array}$} \\
\hline Repeatability ${ }^{c}$ & 0.931 & 0.508 & 0.602 & 0.372 & 0.142 & 0.490 & 0.511 & 0.518 \\
\hline Inter-day precision ${ }^{d}$ & 1.159 & 0.942 & 1.119 & 0.775 & 0.373 & 0.631 & 0.714 & 0.702 \\
\hline
\end{tabular}
extended without any contribution from the interfering drug. This method is advantageous due to its

Table 1 Regression parameters and the results of determination of pure samples of PSE and LOR by the proposed methods

${ }^{\mathrm{a}}$ Six calibration points in $(\mu \mathrm{g} / \mathrm{mL})$, average of three experiments.

$\mathrm{b}_{r}=\sqrt{\mathrm{R}^{2}}$

'Intra-day precision $(n=9)$, average of 3 different concentrations $(200.00,600.00$, and $1000.00 \mu \mathrm{g} / \mathrm{mL})$ for PSE and $(10.00,20.00$, and $25.00 \mu \mathrm{g} / \mathrm{mL})$ for LOR, repeated 3 times each within the same day

${ }^{\mathrm{d}}$ Inter-day precision $(n=9)$, average of 3 different concentrations $(200.00,600.00$, and $1000.00 \mu \mathrm{g} / \mathrm{mL})$ for PSE and $(10.00,20.00$, and $25.00 \mu \mathrm{g} / \mathrm{mL})$ for LOR, repeated 3 times each on 3 successive days 
ability to apply on the mixture's zero-order absorption spectrum without needing divisor.

Dual-wavelength method for PSE (DW) The selection of two wavelengths in which the interfering element shows equal value of absorbance, and the desired element differs significantly in the value of the absorbance with concentration is very important factor to apply dual-wavelength method [43, 44]. As selection of suitable wavelengths regarding sensitivity and selectivity is vital, so different wavelengths were examined, and it was found that the best results concerning sensitivity and selectivity were obtained through the absorbance difference at $254 \mathrm{~nm}$ and $273 \mathrm{~nm}$ for determination of PSE where LOR shows zero absorbance difference (Fig. 3).

In each mixture, PSE concentration was determined through its correlative equation of regression which shows linear correlation between the difference of PSE absorbance at $\left.\Delta A_{254-273 \mathrm{~nm}}\right)$ against the corresponding concentrations $180.0-1200.0 \mu \mathrm{g} / \mathrm{mL}$, and the equation of regression was accurately computed as in Table 1 .

The main drawback of this method is that the measurements of absorbance of the drug of interest were performed at critical wavelengths where interfering drug shows zero interference so any deviation in wavelengths leads to high error which will have a negative effect on the robustness of the method. This method is advantageous due to its ability to apply on the mixture's zero-order absorption spectrum without needing divisor or extension of one of the drugs over the other as in AC method.
Induced dual-wavelength method for PSE (IDW) The principle here is abolishing the interfering element's absorbance between two certain wavelengths. On the contrary of the ordinary dual wavelength method (DW), this method is used when the difference in absorbance $(\Delta A)$ of interfering element is not equal zero [37].

To determine PSE, LOR absorbance should be abolished at the selected two wavelengths. Therefore, induced dual-wavelength method was performed by calculating pure LOR - equality factor at the two selected wavelengths $\left(F=\left[A_{263} / A_{230}\right]=0.778\right)$. Upon using this factor, the absorbance of the interfering component (LOR) will equal zero, while the absorbance of the desired component (PSE) will differ at the two selected wavelengths. Calculation of the difference of absorbance of the mixture's zero-order absorption spectrum was performed at $263 \mathrm{~nm}$ and $230 \mathrm{~nm}$ after multiplication of the absorbance at $230 \mathrm{~nm}$ by the equality factor $F$. This calculated difference of absorbance is linked only to PSE, while LOR is removed, as shown in Fig. 4. The $\Delta A$ values are replaced in the equation of regression which relate $\Delta A\left[A_{263 \mathrm{~nm}}-\right.$ (eq. factor) $\left.A_{230 \mathrm{~nm}}\right]$ versus PSE concentration.

In every mixture, PSE concentration was obtained through using its correlative equation of regression which represents the linear relationship between the difference of PSE absorbance at $\Delta A=A_{263 \mathrm{~nm}}-0.778 A_{230}$ $\mathrm{nm}$ and the correlative concentrations $180.0-1200.0 \mu \mathrm{g} /$ $\mathrm{mL}$; then, the equation of regression was accurately computed as shown in Table 1.

The main benefit of this method is that it has no limitation or requirements as AC method or DW method

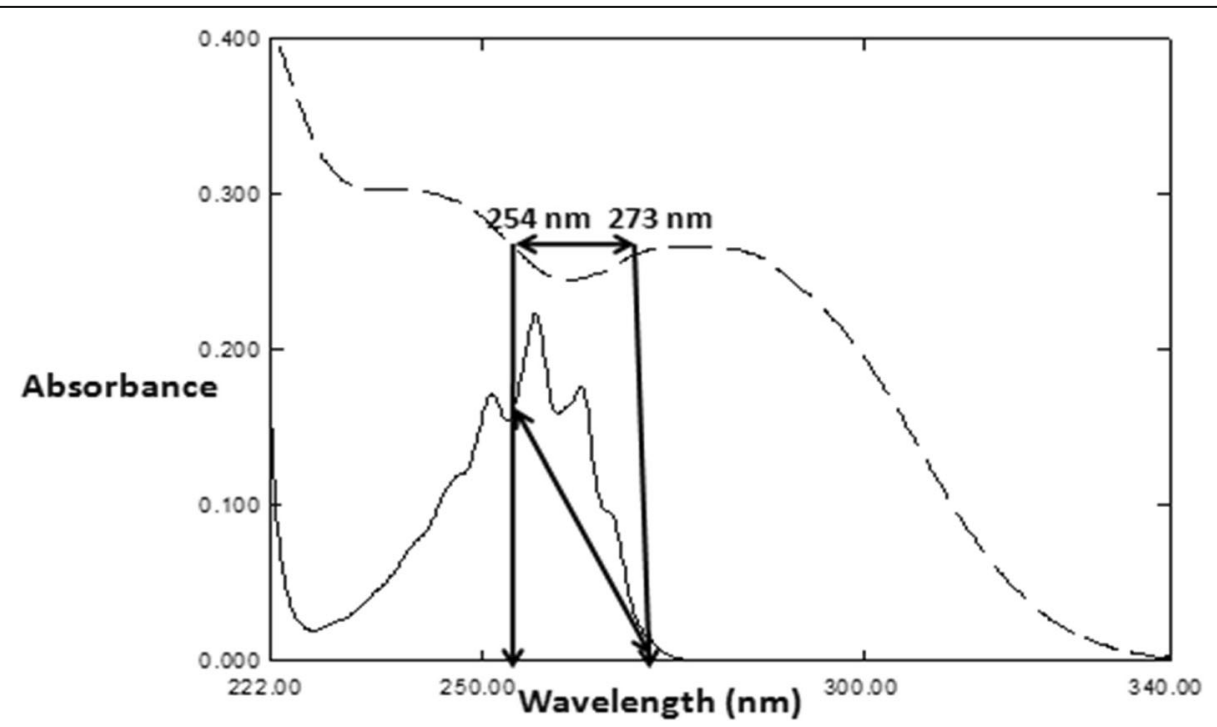

Fig. 3 Zero-order absorption spectra of PSE (s/b d) $240.0 \mu \mathrm{g} / \mathrm{mL}$ and LOR (s/b e) $10.0 \mu \mathrm{g} / \mathrm{mL}$ showing absorbance difference at $254 \mathrm{~nm}$ and $273 \mathrm{~nm}$ 


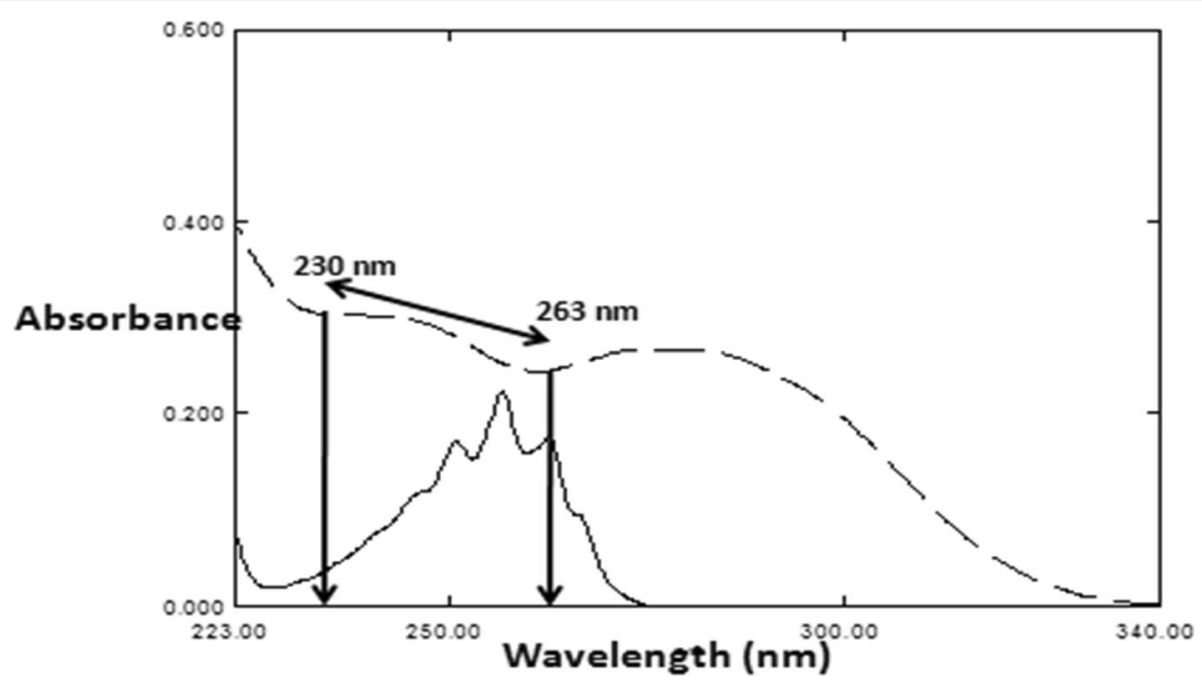

Fig. 4 Zero-order absorption spectra of PSE (s/b f) $240.0 \mu \mathrm{g} / \mathrm{mL}$ and LOR (s/b g) $10.0 \mu \mathrm{g} / \mathrm{mL}$ showing absorbance difference at $230 \mathrm{~nm}$ and $263 \mathrm{~nm}$

and it can be widely applied for a variety of binary mixtures.

\section{Manipulation of the ratio spectra of the mixtures using LOR $(30.0 \mu \mathrm{g} / \mathrm{mL})$ \\ Constant multiplication method paired with spectrum subtraction method (CM-SS)}

The ratio spectrum of every laboratory previously prepared mixture could be obtained using a divisor of LOR $(30.0 \mu \mathrm{g} / \mathrm{mL})$; then, the constant (LOR/LOR') at wavelength region $(277-326 \mathrm{~nm})$ was measured (Fig. 5a). By multiplying the divisor by the previously calculated constant, the spectrum of zero-order absorption of LOR in the mixture was determined then concentration of LOR was obtained by using its correlative regression equation at the two maxima 280 $\mathrm{nm}$ and $250 \mathrm{~nm}$ for LOR (Fig. 5b). This method is advantageous due to its ability to recover the spectra of the zero-order absorption LOR so the resolved spectra which represent spectral profiling of the drug and consequently LOR could be analyzed via their two maxima with best results of accuracy and precision. The resolved spectrum of zero-order absorption of PSE was obtained after subtraction of LOR spectrum (Fig. 5c).

The concentration of LOR in every laboratory previously prepared mixture was determined by using its two correlative regression equations which show linear relation between the values of absorbance of LOR at $\lambda_{250 \mathrm{~nm}}$ and $\lambda_{280 \mathrm{~nm}}$ and the corresponding concentrations $(5.0-30.0 \mu \mathrm{g} / \mathrm{mL})$ for $280 \mathrm{~nm}$.

In every mixture, PSE concentration was determined through its correlative regression equation which shows linear relation between the absorbance values of PSE at its $\lambda_{\max } 256.8 \mathrm{~nm}$ and the corresponding concentrations $(180.0-1200.0 \mu \mathrm{g} / \mathrm{mL})$, and then, the regression equation was accurately computed as shown in Table 1.

The main benefit of this method is getting the original spectrum of the two cited drugs; thus, their concentrations could be obtained using their absorbance at $\lambda_{\max }$ with maximum accuracy and precision. In addition, these recovered spectra act as purity index of the proposed drugs.

\section{Ratio difference method (RD) for PSE}

In this method, the difference of the amplitude between the two selected wavelengths on the mixture's ratio spectra is directly proportional to the desired element's concentration; it does not depend on of the interfering element [45].

After obtaining the scanned mixture's spectrum followed by its division by LOR divisor absorption spectrum, the ratio spectrum represents $\frac{P S E}{L O R^{\prime}}$ constant. Selection of two wavelength for PSE ratio spectra and subtraction of these two amplitudes $\left(\frac{P S E}{L O R}\right) 1-\left(\frac{P S E}{L O R}\right) 2$ were performed so the contribution of the divisor element will be omitted while PSE concentration will be relative directly to the difference. The concentration of PSE in each mixture was determined through its relative equation of regression showing linear relation between the amplitude difference of PSE at $\left(\Delta P_{256.8-270 \mathrm{~nm}}\right)$ against the correlative concentrations $(180.0-1200.0 \mu \mathrm{g} / \mathrm{mL})$.

Accurate selection of the two wavelengths and the divisor is very important. The divisor which will be selected should compromise between negligible noise and maximum sensitivity. The prerequisite of the two selected wavelengths is that the drug of interest has 


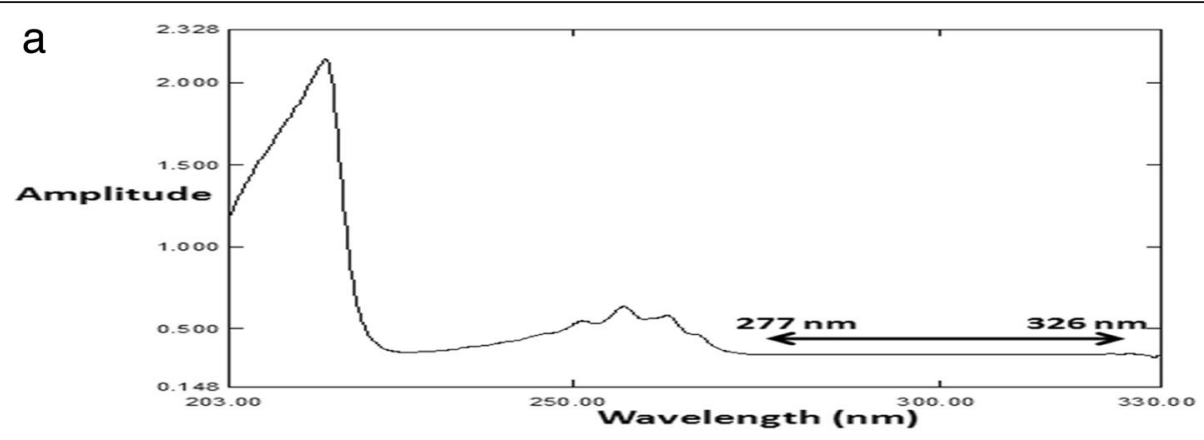

b

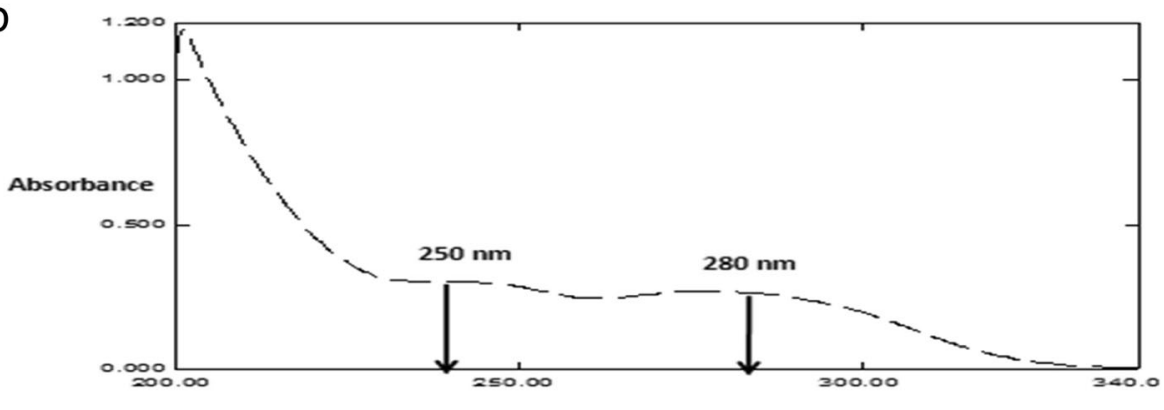

Wavelength (nm)

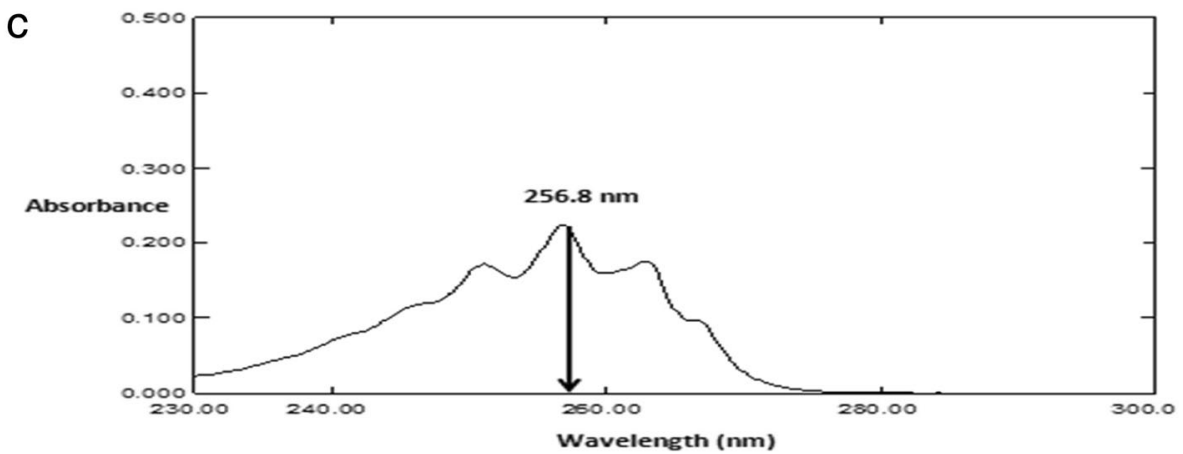

Fig. 5 a Ratio spectrum of binary mixture using LOR $(30.0 \mu \mathrm{g} / \mathrm{mL})$ as a divisor and measure the constant at $277-326 \mathrm{~nm}$. b The obtained zeroorder spectrum of LOR after multiplication by LOR $(30.0 \mu \mathrm{g} / \mathrm{mL})$. c The obtained zero-order spectrum of PSE after spectrum subtraction of LOR spectrum

the highest amplitude difference at the contribution region with the interfering substances, so the selected wavelengths were 256.8 and $270.0 \mathrm{~nm}$ for determination of PSE in each mixture using LOR divisor $(30.0 \mu \mathrm{g} / \mathrm{mL})$ (Fig. 6) and the regression equation was accurately computed as shown in Table 1.

The most remarkable character of the ratio difference method is simplicity with minimum manipulation steps, no need for calculating of mathematic factor as in AC method and IDW method, maximum accuracy, and reproducibility. The RD method is characterized by the ability to analyze the overlapped spectra without any necessary preliminary steps; in addition, it does not need any sophisticated devices or software.

\section{Manipulation of the ratio spectra of the mixtures using} normalized spectra as a divisor Induced amplitude modulation method for determination of PSE and LOR (IAM)

The recently developed (IAM) method [37] was introduced for the severely overlapped spectra. In this work, the newly developed approach was applied concerned with the partially overlapped spectra where one of the spectra was extended than the other one. The first step of the analysis of the mixture is the division by using the normalized divisor of LOR to get the ratio spectra; then, the constant value was measured at wavelength region [277-326 $\mathrm{nm}$ ] which represents the concentration of LOR in 


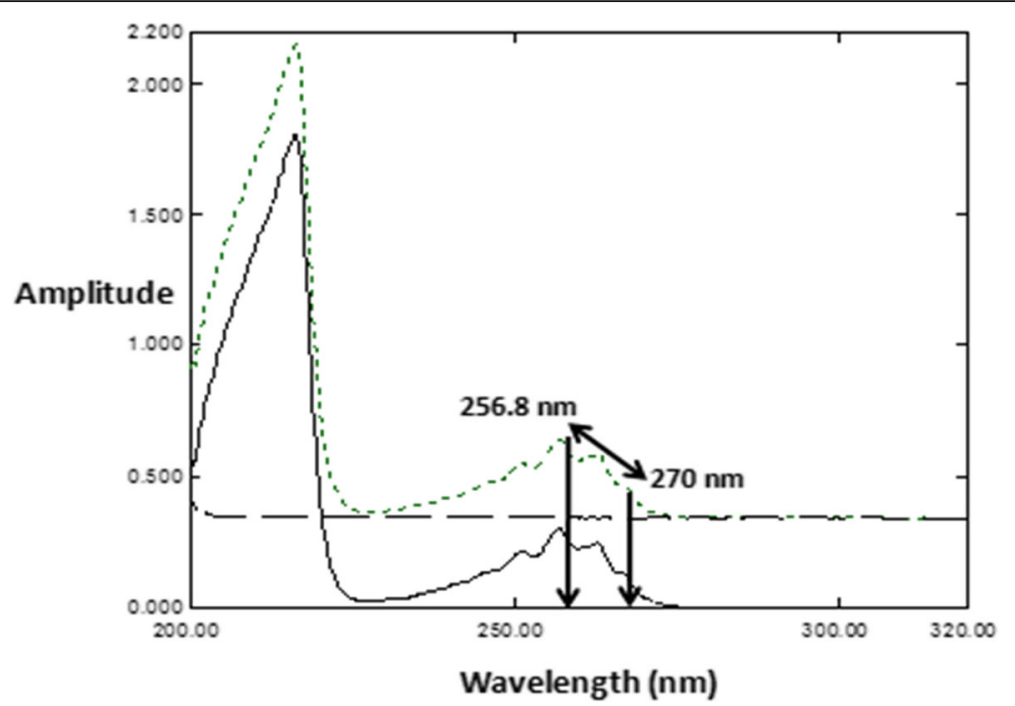

Fig. 6 The amplitude difference at $256.8 \mathrm{~nm}$ and $270 \mathrm{~nm}(\Delta \mathrm{P} 256.8-270 \mathrm{~nm})$ of ratio spectrum of binary mixture of PSE and LOR (s/b h), LOR (s/b i) $10.0 \mu \mathrm{g} / \mathrm{mL}$, and PSE (s/b j) $240.0 \mu \mathrm{g} / \mathrm{mL}$ using LOR (30 $\mu \mathrm{g} / \mathrm{mL})$ as a divisor

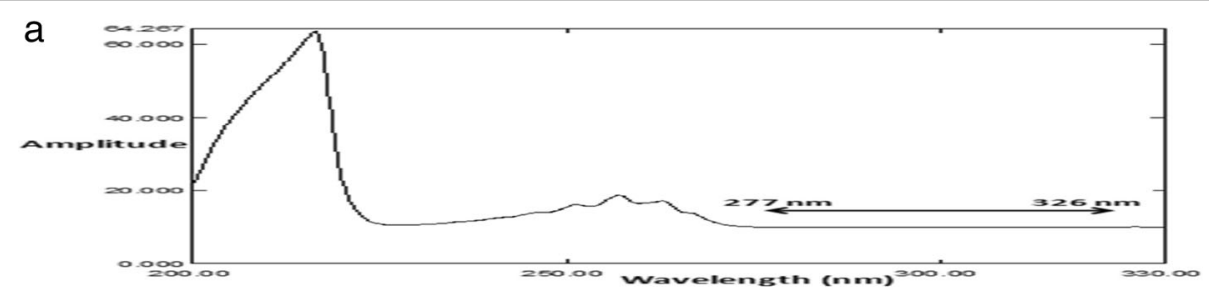

b

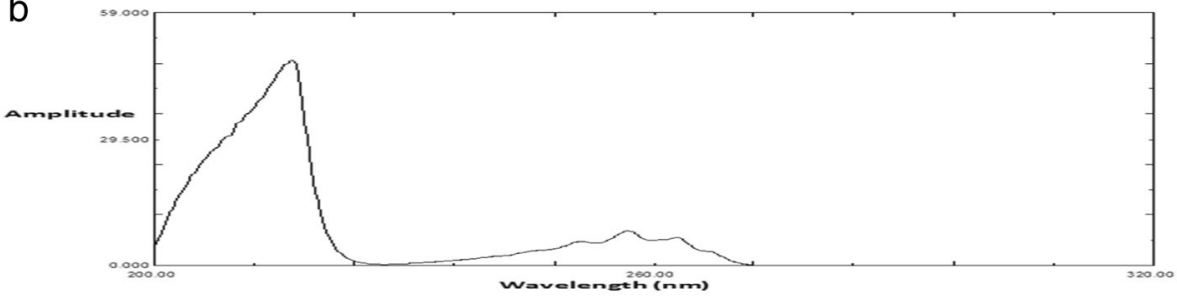

C

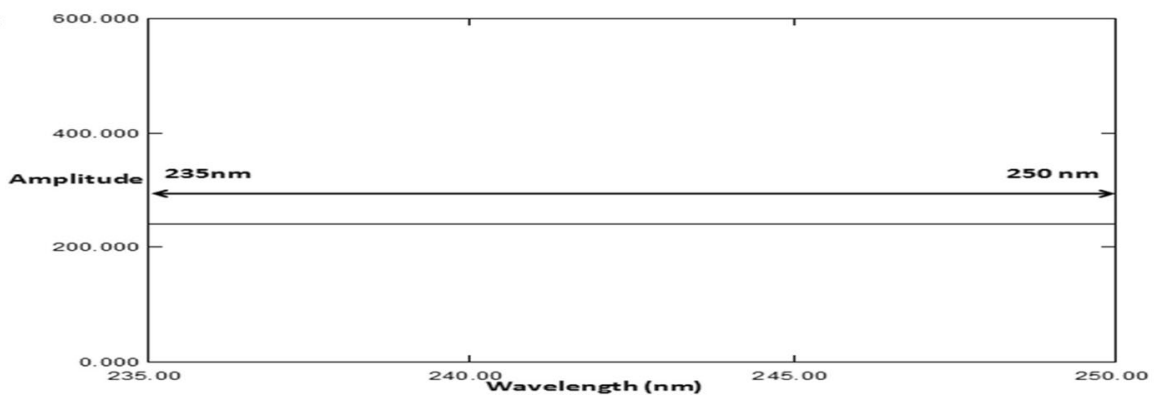

Fig. 7 a Ratio spectrum of binary mixture $240.0 \mu \mathrm{g} / \mathrm{mL}$ of PSE and $10.0 \mu \mathrm{g} / \mathrm{mL}$ of LOR using spectrum of normalized LOR' as a divisor showing the value of constant at $(277-326 \mathrm{~nm})$. b The obtained ratio spectrum of binary mixture after subtraction of the constant value. c The obtained ratio spectrum of binary mixture after multiplication by recovery spectrum (normalized spectrum of LOR/normalized spectrum of PSE) showing the value of constant at $235-250 \mathrm{~nm}$ 
Table 2 Determination of PSE and LOR in the laboratory-prepared mixtures by the proposed spectrophotometric methods

\begin{tabular}{|c|c|c|c|c|c|c|c|c|c|c|c|}
\hline \multicolumn{12}{|c|}{$\%$ Recovery $^{\mathrm{a}} \pm$ SD } \\
\hline \multicolumn{2}{|c|}{ LOR:PSE } & \multicolumn{6}{|l|}{ PSE } & \multicolumn{4}{|l|}{ LOR } \\
\hline \multirow[t]{2}{*}{ Ratio } & \multirow{2}{*}{$\begin{array}{l}\text { Concentrations } \\
(\mu \mathrm{g} / \mathrm{mL})\end{array}$} & \multirow[t]{2}{*}{ IAM } & \multirow{2}{*}{$\begin{array}{l}\text { AC } \\
(256.8 \mathrm{~nm})\end{array}$} & \multirow[t]{2}{*}{ DW } & \multirow[t]{2}{*}{ IDW } & \multirow[t]{2}{*}{$\mathrm{RD}$} & \multirow{2}{*}{$\begin{array}{l}D^{0} \text { at } \\
256.8 \mathrm{~nm}^{c} \\
\text { (SS) }\end{array}$} & \multirow[t]{2}{*}{ IAM } & \multicolumn{2}{|l|}{$C M$} & \multirow{2}{*}{$\begin{array}{l}D^{0} \text { at } 280 \\
n^{d}\end{array}$} \\
\hline & & & & & & & & & $\begin{array}{l}\mathrm{D}^{0} \text { at } 280 \\
\mathrm{~nm}\end{array}$ & $\begin{array}{l}\mathrm{D}^{0} \text { at } 250 \\
\mathrm{~nm}\end{array}$ & \\
\hline$(1: 24)^{b}$ & $10: 240$ & 99.43 & 99.52 & 100.07 & 99.83 & 100.26 & 101.23 & 100.58 & 101.28 & 99.75 & 100.20 \\
\hline$(1: 12)$ & $15: 180$ & 99.18 & 100.57 & 100.14 & 99.79 & 100.13 & 100.54 & 100.78 & 99.24 & 100.31 & 100.12 \\
\hline$(1: 18)$ & $10: 180$ & 99.70 & 99.87 & 100.12 & 100.31 & 100.10 & 100.34 & 100.55 & 100.67 & 100.07 & 100.20 \\
\hline$(1: 30)$ & $20: 600$ & 101.15 & 99.69 & 99.41 & 100.09 & 99.99 & 101.03 & 100.64 & 101.35 & 100.35 & 100.84 \\
\hline$(1: 48)$ & $5: 240$ & 99.92 & 100.76 & 100.00 & 100.07 & 100.02 & 100.43 & 99.75 & 100.77 & 100.65 & 99.25 \\
\hline $\begin{array}{l}\text { Mean } \pm \\
\text { SD }\end{array}$ & & $\begin{array}{l}99.88 \pm \\
0.76\end{array}$ & $\begin{array}{l}100.08 \pm \\
0.55\end{array}$ & $\begin{array}{l}99.95 \pm \\
0.31\end{array}$ & $\begin{array}{l}100.02 \pm \\
0.21\end{array}$ & $\begin{array}{l}100.10 \pm \\
0.11\end{array}$ & $\begin{array}{l}100.71 \pm \\
0.39\end{array}$ & $\begin{array}{l}100.46 \pm \\
0.41\end{array}$ & $\begin{array}{l}100.66 \pm \\
0.85\end{array}$ & $\begin{array}{l}100.23 \pm \\
0.34\end{array}$ & $\begin{array}{l}100.12 \pm \\
0.57\end{array}$ \\
\hline
\end{tabular}

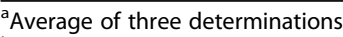

${ }^{\mathrm{b}}$ Ratio of the cited drugs as in the dosage form

${ }^{\mathrm{C}}$ Direct measurement of PSE at $256.8 \mathrm{~nm}$ after spectrum subtraction of LOR

${ }^{\mathrm{d}}$ Direct measurement of LOR at $280 \mathrm{~nm}$

the mixture as shown in Fig. 7a. The concentration of PSE was obtained after subtraction of the constant value of LOR from the mixture ratio spectrum (Fig. 7b). The ratio spectrum was obtained which represent $\left[\begin{array}{ll}a_{\mathrm{PSE}} & c_{\mathrm{PSE}}\end{array}\right] / a_{\mathrm{LOR}^{\prime}}$. Multiplication of the gained ratio spectra by the recovery spectrum representing the absorptivity ratio $a_{\mathrm{r}}\left[\left(a_{\mathrm{LOR}} / a_{\mathrm{PSE}^{\prime}}\right)\right.$ obtained by dividing the normalized spectra of LOR by normalized spectra of PSE] was performed and straight line $\left(a_{\mathrm{PSE}} / a_{\mathrm{PSE}}\right)$ parallel to $X$-axis, which represents PSE concentration, as shown in Fig. 7c.

The actual concentrations of PSE and LOR were obtained by direct modulation of their recorded concentrations using the following equations of regression:

$$
\begin{aligned}
& C_{\text {Recorded }}=1.001 C_{\text {Actual }}+0.156 \text { for PSE } \\
& C_{\text {Recorded }}=0.9847 C_{\text {Actual }}+0.0749 \text { for LOR }
\end{aligned}
$$

$C_{\text {Recorded }}$ is the amplitude which was recorded for the ratio spectra. It is linked to PSE and LOR concentrations using normalized spectrum of LOR and PSE, conjointly as a divisor, and $C_{\text {Actual }}$ is the actual PSE and LOR concentration.

In each mixture, LOR concentration was determined using its correlative regression equation which shows linear relation between peak amplitudes of LOR and the correlative concentrations $(5.0-30.0 \mu \mathrm{g} / \mathrm{mL})$ using normalized LOR' spectrum as a divisor, while the concentration of PSE in each mixture was determined through using its correlative equation of regression which show linear relation between PSE peak amplitudes and the correlative concentrations $(180.0-1200.0 \mu \mathrm{g} / \mathrm{mL})$ using normalized PSE' spectrum as a divisor, and the equation of regression was accurately computed as shown in Table 1.

Satisfactory results concerning their pure powdered forms, synthetic mixtures, and the pharmaceutical formulation without needing preliminary separation were obtained.

The IAM method differs from AM method and AAM method as one component is extended than the other and it can analyze mixtures which is lacking the existence of an isoabsorptive point. Also, it can directly modulate both component's ratio amplitudes into their related concentrations. This could be

Table 3 Determination of the studied drugs in the tablet dosage form (Clarinase ${ }^{\oplus}$ ) and the application of standard addition

\begin{tabular}{|c|c|c|c|c|c|c|c|c|c|c|}
\hline & \multicolumn{6}{|l|}{ PSE } & \multicolumn{4}{|l|}{ LOR } \\
\hline & \multirow[t]{2}{*}{$\mid A M$} & \multirow[t]{2}{*}{$A C$} & \multirow[t]{2}{*}{ DW } & \multirow[t]{2}{*}{ IDW } & \multirow[t]{2}{*}{$\mathrm{RD}$} & \multirow{2}{*}{$\begin{array}{l}\mathrm{D}^{0} \text { at } \\
256.8 \\
\mathrm{~nm}^{\mathrm{c}}(\mathrm{SS})\end{array}$} & \multirow[t]{2}{*}{ IAM } & \multicolumn{2}{|l|}{$\mathrm{CM}$} & \multirow{2}{*}{$\begin{array}{l}\mathrm{D}^{0} \text { at } 280 \\
\mathrm{~nm}^{\mathrm{d}}\end{array}$} \\
\hline & & & & & & & & $\begin{array}{l}\text { At } 280 \\
\mathrm{~nm}\end{array}$ & $\begin{array}{l}\text { At } 250 \\
\mathrm{~nm}\end{array}$ & \\
\hline $\begin{array}{l}\text { Pharmaceutical dosage form }{ }^{b} \\
\text { (found } \% \pm S D \text { ) }\end{array}$ & $\begin{array}{l}100.55 \pm \\
0.15\end{array}$ & $\begin{array}{l}99.76 \pm \\
0.16\end{array}$ & $\begin{array}{l}99.40 \pm \\
0.29\end{array}$ & $\begin{array}{l}99.31 \pm \\
0.16\end{array}$ & $\begin{array}{l}100.08 \pm \\
0.19\end{array}$ & $\begin{array}{l}98.74 \pm \\
0.41\end{array}$ & $\begin{array}{l}99.98 \pm \\
0.11\end{array}$ & $\begin{array}{l}100.93 \pm \\
0.30\end{array}$ & $\begin{array}{l}100.32 \pm \\
0.05\end{array}$ & $\begin{array}{l}100.00 \pm \\
0.21\end{array}$ \\
\hline $\begin{array}{l}\text { Standard Addition }{ }^{\mathrm{a}} \text { (recovery } \% \pm \\
\text { SD) }\end{array}$ & $\begin{array}{l}99.91 \pm \\
1.07\end{array}$ & $\begin{array}{l}99.47 \pm \\
1.27\end{array}$ & $\begin{array}{l}99.96 \pm \\
0.96\end{array}$ & $\begin{array}{l}100.19 \pm \\
0.71\end{array}$ & $\begin{array}{l}100.31 \pm \\
0.68\end{array}$ & $\begin{array}{l}99.88 \pm \\
0.44\end{array}$ & $\begin{array}{l}100.37 \pm \\
0.67\end{array}$ & $\begin{array}{l}101.49 \pm \\
0.54\end{array}$ & $\begin{array}{l}100.34 \pm \\
1.07\end{array}$ & $\begin{array}{l}100.71 \pm \\
0.96\end{array}$ \\
\hline
\end{tabular}
technique by the proposed methods

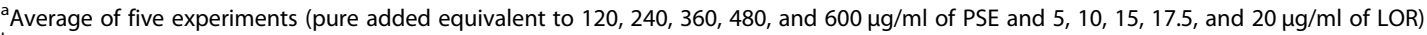

${ }^{\mathrm{b}}$ Average of three experiments

'Direct measurement of PSE at $256.8 \mathrm{~nm}$ after spectrum subtraction of LOR

${ }^{\mathrm{d}}$ Direct measurement of LOR at $280 \mathrm{~nm}$ 
Table 4 Statistical comparison of the results obtained by the proposed spectrophotometric methods and those obtained by the official ones for the determination of PSE and LOR in their pure powdered forms

\begin{tabular}{|c|c|c|c|c|c|c|c|c|c|c|}
\hline \multirow[t]{2}{*}{ Parameters } & \multicolumn{6}{|l|}{ PSE } & \multicolumn{4}{|l|}{ LOR } \\
\hline & $\begin{array}{l}\mathrm{D}^{0} \text { at } 256.8 \mathrm{~nm} \\
\text { (SS) }\end{array}$ & DW & IDW & $\mathrm{RD}$ & IAM & $\begin{array}{l}\text { Official } \\
\text { method }^{\mathrm{a}}\end{array}$ & $\begin{array}{l}\mathrm{D}^{0} \\
(280 \mathrm{~nm}) \\
\text { (Direct measurement } \\
\text { or CM) }\end{array}$ & $\begin{array}{l}\mathrm{D}^{0}(250 \\
\mathrm{nm}) \\
(\mathrm{CM})\end{array}$ & IAM & $\begin{array}{l}\text { Official } \\
\text { method }^{a}\end{array}$ \\
\hline Mean & 100.07 & 100.12 & 100.09 & 99.64 & 99.72 & 99.53 & 100.10 & 99.82 & 99.98 & 100.06 \\
\hline SD & 0.69 & 0.67 & 0.76 & 0.65 & 0.22 & 0.42 & 0.68 & 0.47 & 0.62 & 0.75 \\
\hline N & 7 & 7 & 7 & 7 & 7 & 6 & 7 & 7 & 7 & 7 \\
\hline Variance & 0.4761 & 0.4489 & 0.5776 & 0.4225 & 0.0484 & 0.1764 & 0.4624 & 0.2209 & 0.3844 & 0.5625 \\
\hline $\begin{array}{l}\text { Student's } t \\
\text { test }^{\mathrm{b}}\end{array}$ & $1.665(2.201)$ & $\begin{array}{l}1.860 \\
(2.201)\end{array}$ & $\begin{array}{l}1.601 \\
(2.201)\end{array}$ & $\begin{array}{l}0.355 \\
(2.201)\end{array}$ & $\begin{array}{l}1.046 \\
(2.201)\end{array}$ & & $0.104(2.179)$ & $\begin{array}{l}0.717 \\
(2.179)\end{array}$ & $\begin{array}{l}0.217 \\
(2.179)\end{array}$ & \\
\hline$F$ test $^{\mathrm{b}}$ & $2.70(4.95)$ & $\begin{array}{l}2.54 \\
(4.95)\end{array}$ & $\begin{array}{l}3.27 \\
(4.95)\end{array}$ & $2.40(4.95)$ & $\begin{array}{l}3.64 \\
(4.39)\end{array}$ & & $1.22(4.28)$ & $\begin{array}{l}2.55 \\
(4.28)\end{array}$ & $\begin{array}{l}1.46 \\
(4.28)\end{array}$ & \\
\hline
\end{tabular}

aSP methods for LOR is a HPLC method (using C18 column and mixture of dibasic potassium phosphate, methanol, and acetonitrile (7:6:6) as mobile phase with flow rate $1 \mathrm{~mL} / \mathrm{min}$ ), while for PSE is potentiometric titration method (using glacial acetic acid as a solvent and $0.1 \mathrm{~N}$ perchloric acid as a titrant) [38]

${ }^{\mathrm{b}}$ The figures in parenthesis are the corresponding theoretical values at $P=0.05$ [47]

achieved by using a constant which is parallel along with $X$-axis. The concentrations can be determined easily over the whole $X$-axis, not at definite point.

\section{Method validation}

Validation was performed relative to the guidelines of ICH [46] as revealed in Table 1.

\section{Linearity}

The linearity of the proposed methods was assessed through analyzing different concentrations of PSE and LOR ranging from 180.0 to $1200.0 \mu \mathrm{g} / \mathrm{ml}$ and 5.0 to $30.0 \mu \mathrm{g} / \mathrm{mL}$, conjointly. Replication of each concentration was conducted three times. The analysis was performed as per the previously mentioned experimental conditions. Demonstration of linear equations is conducted in Table 1.

\section{Range}

The range of the calibration was performed through using the practical range necessary according to Beer's law and the concentration of both PSE and LOR which present in their combined dosage form to give linear, precise, and accurate results (Table 1).

\section{Accuracy}

Accuracy was investigated by applying the proposed methods for determination of various samples of PSE and LOR, and the standard addition technique was performed where various known concentrations of pure standard PSE and LOR were added to the pharmaceutical formulation before proceeding the previously mentioned methods. Obtaining the concentrations of both PSE and LOR were performed using the relative equations of regression. Good accuracy of the proposed spectrophotometric methods was obtained. This was shown by the obtained percentages of recovery (Table 1).

\section{Precision}

\section{Repeatability and inter-day precision}

They could be determined by using three concentrations of PSE and LOR separately; then, they were

Table 5 ANOVA (single factor) for comparison of the results of the proposed spectrophotometric methods and those of the official methods for determination of PSE and LOR in pure powdered forms

\begin{tabular}{|c|c|c|c|c|c|c|}
\hline Source of variation & Sum of squares & DF & Mean square & $F$ value & $P$ value & F crit \\
\hline \multicolumn{7}{|l|}{ PSE } \\
\hline Between exp. & 3.386712 & 5 & 0.67734 & 1.862518 & 0.126191 & 2.485143 \\
\hline Within exp. & 12.72846 & 35 & 0.36367 & & & \\
\hline Total & 16.11517 & 40 & & & & \\
\hline \multicolumn{7}{|l|}{ LOR } \\
\hline Between exp. & 0.319743 & 3 & 0.106581 & 0.261691 & 0.852267 & 3.008787 \\
\hline Within exp. & 9.774657 & 24 & 0.407277 & & & \\
\hline Total & 10.0944 & 27 & & & & \\
\hline
\end{tabular}

At the 0.05 level [46]. The population means are not significantly different 
examined intra-daily and inter-daily three times on three different days using the proposed spectrophotometric methods. The correlating standard deviations which are correlative to every concentration were computed (Table 1).

\section{Selectivity}

Selectivity of the proposed methods was ascertained by the analysis of various synthetic mixtures containing different ratios of cited drugs within the linearity range PSE and LOR within the linearity range. Acceptable results are revealed in Table 2 .

\section{Application of the proposed analytical methods in assessment of Clarinase $^{\oplus}$ tablet}

The proposed spectrophotometric methods were used for the determination of concentration of both PSE and LOR in their combined dosage form, Clarinase tablet ${ }^{\circ}$, and the results are revealed in Table 3, and the validity of the proposed procedures is further evaluated by applying the technique of standard addition showing no interference from excipients. Good percentage recoveries were showed for all the proposed methods, and this allows for their use of regular PSE and LOR analysis in their combined formulation. The obtained results are revealed in Table 3.

\section{Statistical analysis}

The comparison of the statistical data obtained by the proposed analytical methods and those by the official USP methods [38] for pure powder showed insignificant differences as revealed in Table 4 . To relate the capability of the proposed methods for the determination of PSE and LOR, the results attained by applying the proposed methods were subjected to statistical analysis through one-way ANOVA test for pure powder and all the proposed analytical methods were insignificant differing between each other (Table 5).

\section{Conclusions}

In this work, rapid, precise, and accurate spectrophotometric methods were applied for concurrent determination of PSE and LOR in their pure powdered form, prepared mixtures in laboratory, and pharmaceutical formulation through using various manipulation steps for either measurement directly at the spectra of zero-order absorption or to restore their spectra of zero-order absorption.

The validation of the proposed methods was performed using the guidelines of $\mathrm{ICH}$, and satisfactory results were obtained. Those methods could also be conducted in laboratories of the quality control for regular PSE and LOR analysis. The results were subjected to the statistical comparison to each other and also to the official methods of authentic drugs, and insignificant difference was obtained.

\section{Abbreviations}

CM: Constant multiplication; DW: Dual wavelength; IAM: Induced amplitude modulation; IDW: Induced dual wavelength; ICH: International Conference on Harmonization; LOR: Loratadine; PSE: Pseudoephedrine sulphate; RD: Ratio difference; USP: United State Pharmacopeia

\section{Acknowledgements}

Not applicable for that section.

Authors' contributions

$\mathrm{HL}$ and MA conceived of the study and performed the design of this work. SE carried out the practical work and wrote the manuscript. YF performed the statistical analysis. MA, HL, and YF revised the final manuscript. All authors read and approved the final manuscript.

Funding

Not applicable for that section

Availability of data and materials

All data generated or analyzed during this study are included in this published article.

Ethics approval and consent to participate

Not applicable for that section.

Consent for publication

Not applicable for that section.

\section{Competing interests}

The authors declare that they have no competing interests.

\section{Author details}

${ }^{1}$ Pharmaceutical Chemistry Department, Faculty of Pharmaceutical Sciences and Pharmaceutical Industries, Future University in Egypt, End of 90th St., 5th Settlement, New Cairo, Cairo 11835, Egypt. ${ }^{2}$ Analytical Chemistry

Department, Faculty of Pharmacy, Cairo University, Giza, Egypt.

Received: 14 July 2019 Accepted: 1 August 2019

Published online: 02 September 2019

\section{References}

1. Reynolds, J. E. (1982). Martindale: the extra pharmacopoeia, London, UK; The Pharmaceutical Press.

2. Lotfy HM, Fayz YM, El-Hanboushy S, Shokry E, Abdelkawy M (2016) Application of successive and progressive spectrophotometric resolution for the analysis of partially or completely overlapping ternary mixtures. Anal Chem Lett 6(6):718-737

3. Riahi S, Hadiloo F, Milani SMR, Davarkhah N, Ganjali MR, Norouzi P, Seyfi P (2011) A new technique for spectrophotometric determination of pseudoephedrine and guaifenesin in syrup and synthetic mixture. Drug Test Anal 3(5):319-324

4. Souri E, Mosafer A, Tehrani MB (2016) Fourth-order derivative spectrophotometric method for simultaneous determination of pseudoephedrine and naproxen in pharmaceutical dosage forms. Res Pharm Sciences 11(2):93-99

5. Abdelwahab NS, Abdelaleem EA (2017) Stability indicating RP-HPLC method for simultaneous determination of guaifenesin and pseudoephedrine hydrochloride in the presence of syrup excepients. Arab J Chem 10:S2896-\$2901

6. Abro K, Memon N, Bhanger M, Perveen S, Kandhro A (2012) Multicomponent quantitation of loratadine, pseudoephedrine and paracetamol in plasma and pharmaceutical formulations with liquid chromatography-tandem mass spectrometry utilizing a monolithic column. Quimica Nova 35(10):1950-1954

7. An Q, Dong Y-m, Lu N-w, Li N (2017) Micellar liquid chromatographic method for the determination of ephedrine and pseudoephedrine in 
human serum by direct inject of the sample with simple dilution. J Liq Chrom Relat Technol:1-7

8. Kayesh R, Sarker A, Sultan MZ, Jahan MS (2017) A simple and improved HPLC-PDA method for simultaneous estimation of fexofenadine and pseudoephedrine in extended release tablets by response surface methodology. J Chem 2017

9. YANG C (2006) HPLC simultaneous determination of acetaminophenpseudoephedrinesulfate and loratadine in compound sustainedrelease tablets. Chin J Pharm Anal 26(11):1652-1655

10. Yolanda M, Martono S, Rohman A (2016) Validation of an ion-pair high performance liquid chromatography for the determination of pseudoephedrine $\mathrm{HCl}$, guaifenesin and dexchlorpheniramine maleat in cough and cold medicines. Int J Pharm Clin Res 8(5):476-480

11. Abdelwahab N, Abdelaleem E (2013) TLC-densitometric determination of guaifenesin, pseudoephedrine hydrochloride and guaifenesin related substance (guaiacol). JPC-Journal of Planar Chromatography-Modern TLC 26(1):73-77

12. El-Kommos ME, El-Gizawy SM, Atia NN, Hosny NM (2014) Thin layer chromatography-densitometric determination of some non-sedating antihistamines in combination with pseudoephedrine or acetaminophen in synthetic mixtures and in pharmaceutical formulations. Biomed Chromatogr 28(3): $391-400$

13. Farid NF, Abdelaleem EA (2016) HPTLC Method for the Determination of Paracetamol, Pseudoephedrine and Loratidine in Tablets and Human Plasma. J Chromatogr Sci:bmv184

14. Gunn J, Kriger S, Terrell AR (2010) Identification and quantitation of amphetamine, methamphetamine, MDMA, pseudoephedrine, and ephedrine in blood, plasma, and serum using gas chromatographymass spectrometry (GC/MS). Methods Mol Biol 603:37-43

15. MI KA, Khuhawar M (2009) Ethyl chloroformate as derivatizing reagent for gas chromatographic determination of norephedrine, ephedrine and pseudoephedrine in pharmaceutical preparation. Asian J Chem 21(2):1145-1154

16. Liu YM, Tian W, Jia YX, Yue HY (2009) Simultaneous determination of methylephedrine and pseudoephedrine in human urine by CE with electrochemiluminescence detection and its application to pharmacokeinetics. Biomed Chromatogr 23(11):1138-1144

17. Deng D, Deng H, Zhang L, Su Y (2014) Determination of ephedrine and pseudoephedrine by field-amplified sample injection capillary electrophoresis. J Chromatogr Sci 52(4):357-362

18. Ganjali MR, Alipour A, Riahi S, Larijani B, Norouzi P (2009) Quantitative analysis of pseudoephedrine in formulation by potentiometric membrane sensor; computational investigation. Int J Electrochem Sci 4:1262-1276

19. Hameed RMA (2018) A core-shell structured Ni-Co@Pt/C nanocomposite modified sensor for the voltammetric determination of pseudoephedrine $\mathrm{HCl}$. New J Chem 42:2658-2668

20. Zayed S, Issa Y, Hussein A (2006) Construction and performance characterization of ionselective electrodes for potentiometric determination of pseudoephedrine hydrochloride applying batch and flow injection analysis techniques. Annali di chimica 96(7-8):421-433

21. Hassaninejad-Darzi SK, Samadi-Maybodi A, Nikou SM (2016) UV-vis spectrophotometry and multivariate calibration method for simultaneous determination of theophylline, montelukast and loratadine in tablet preparations and spiked human plasma. Iran J Pharm Res 15(3):379-391

22. Singh SK (2015) Validation of isocratic RP-HPLC method and UV spectrophotometric method for the estimation of loratadine in pharmaceutical formulations. Res J Pharm Technol 8(4):452-461

23. Akram S, Ali S, Qayoom A, Iqbal S, Naz N, Memon I (2017) High performance liquid chromatographic method for simultaneous determination of alprazolam with antihistamines in bulk drug, pharmaceutical formulation and human serum. Sindh Univ Res J 49(1):7-12

24. Belal F, El-Razeq SA, El-Awady M, Zayed S, Barghash S (2016) Rapid micellar HPLC analysis of loratadine and its major metabolite desloratadine in nano-concentration range using monolithic column and fluorometric detection: application to pharmaceuticals and biological fluids. Chem Centr J 10(1):79

25. Pavalache G, Dorneanu V, Popescu A (2015) Validation and application of a new DAD-HPLC method for determination of loratadine from pharmaceuticals. Farmacia 63(3):366-370

26. Chavhan ML, Shirkhedkar AA, Surana SJ (2017) Development and validation of a stability indicating RP-TLC/densitometric method for determination of loratadine in bulk and in tablets. Arab J Chem 10:5825-\$830

27. Johnson R, Christensen J, Lin C-C (1994) Sensitive gas — liquid chromatographic method for the determination of loratadine and its major active metabolite, descarboethoxyloratadine, in human plasma using a nitrogen—-phosphorus detector. J Chromatogr B Biomed Sci Appl 657(1):125-131

28. Martens J (1995) Determination of loratadine and pheniramine from human serum by gas chromatography-mass spectrometry. J Chromatogr B Biomed Sci Appl 673(2):183-188

29. Eisele APP, Sartori ER (2015) Simple and rapid determination of loratadine in pharmaceuticals using square-wave voltammetry and a cathodically pretreated boron-doped diamond electrode. Anal Methods 7(20):8697-8703

30. Mashhadizadeh M, Hadjiakhoondi A, Ahmadaghaei S (2011) A novel PVC membrane sensor for determination of loratadine in pharmaceutical compounds and blood serum. J Iran Chem Soc 8(3):687-693

31. Norouzi P, Ganjali M (2008) A new method for the determination of loratadine at an Au microelectrode in flowing systems with the use of fast continuous cyclic voltammetry. J Anal Chem 63(6):566-573

32. Roushani M, Nezhadali A, Jalilian Z, Azadbakht A (2017) Development of novel electrochemical sensor on the base of molecular imprinted polymer decorated on SiC nanoparticles modified glassy carbon electrode for selective determination of loratadine. Mater Sci Eng C 71:1106-1114

33. Mabrouk M, El-Fatatry H, Hammad S, Wahbi AAM (2003) Simultaneous determination of loratadine and pseudoephedrine sulfate in pharmaceutical formulation by RP-LC and derivative spectrophotometry. J Pharm Biomed Anal 33(4):597-604

34. Reid IOA, Gadkariem EA (2017) Simultaneous determination of pseudoephedrine and loratadine in syrups by HPLC using cation exchange column and experimental design optimization. Pharm Innov 6(3, Part D):244-247

35. Singhvi I, Bhati N (2006) Spectrophotometric and HPLC methods for simultaneous estimation of pseudoephedrine hydrochloride and loratadine from tablets. Indian J Pharm Sci 68(1):72-75

36. Palabiyik I, Onur F (2007) Simultaneous spectrophotometric determination of pseudoephedrine sulphate and loratadine in a pharmaceutical preparation using chemometric techniques. Ankara Universitesi Eczacilik Fakultesi Dergisi 36(3):171-182

37. Lotfy HM, Saleh SS, Hassan NY, Salem H (2015) Novel two wavelength spectrophotometric methods for simultaneous determination of binary mixtures with severely overlapping spectra. Spectrochim Acta A Mol Biomol Spectrosc 136:1786-1796

38. USP (2016). United States Pharmacopeia and National Formulary (USP 39-NF 34).

39. Culzoni MJ, Goicoechea HC (2007) Determination of loratadine and pseudoephedrine sulfate in pharmaceuticals based on non-linear second-order spectrophotometric data generated by a pH-gradient flow injection technique and artificial neural networks. Anal Bioanal Chem 389(7-8):2217-2225

40. Onur F, Yücesoy C, Dermiş S, Kartal M, Kökdil G (2000) Simultaneous determination of pseudoephedrine sulfate, dexbrompheniramine maleate and loratadine in pharmaceutical preparations using derivative spectrophotometry and ratio spectra derivative spectrophotometry. Talanta 51(2):269-279

41. Patel CV, Khandhar AP, Captain AD, Patel KT (2007) Validated absorption factor spectrophotometric and reversed-phase high-performance liquid chromatographic methods for the determination of ramipril and olmesartan medoxomil in pharmaceutical formulations. Eurasian J Anal Chem 2(3):159-171

42. Prajapati J, Patel M, Prajapati N, Prajapati R (2011) Simultaneous determination of perindopril erbumine and amlodipine besylate by absorption factor method. Int J Appl Biol Pharm Technol 2:230-233

43. M. Lotfy, H., S. M. Tawakkol, N. M. Fahmy and M. A. Shehata (2013). Validated stability indicating spectrophotometric methods for the determination of lidocaine hydrochloride, calcium dobesilate, and dexamethasone acetate in their dosage forms. Inte J ChemTech Res 3(3): 208-225.

44. Ramadan NK, Mohamed HM, Moustafa AA (2011) Simultaneous determination of rabeprazole sodium and domperidone. J Appl Pharm Sci 1(9):73-80

45. Lotfy HM, Hagazy MA-M (2012) Comparative study of novel spectrophotometric methods manipulating ratio spectra: an application on pharmaceutical ternary mixture of omeprazole, tinidazole and clarithromycin. Spectrochim Acta A Mol Biomol Spectrosc 96:259-270

46. ICH (1997). International Conference on Harmonization (ICH), Q2B : Validation of analytical procedures: Methodology,62,US FDA Federal Register.

47. MR S, L S (1999) Theory and problems of statistics. Schaum's Outline Series, pp 345-349

\section{Publisher's Note}

Springer Nature remains neutral with regard to jurisdictional claims in published maps and institutional affiliations. 